(c) 2007 Elsevier Ltd All rights reserved.

\title{
Validity and limitations of linear analytical models for steel wire strands under axial loading, using a 3D FE model
}

\author{
Seyed Reza Ghoreishi ${ }^{a},{ }^{*}$, Tanguy Messager $^{\mathrm{a}, \mathrm{b}}$, Patrice Cartraud ${ }^{\mathrm{a}}$ and Peter Davies ${ }^{\mathrm{c}}$ \\ a Institut de recherche en Génie civil et Mécanique (GéM), Ecole Centrale de Nantes, BP92101, 44321 Nantes, \\ France \\ ${ }^{\mathrm{b}}$ Université de Nantes, Nantes Atlantique Universités, France \\ ${ }^{c}$ IFREMER, Materials and Structures group, BP70, 29280 Plouzané, France \\ *: Corresponding author : Goreishi R., email address : reza_ghoreishi@yahoo.com
}

\begin{abstract}
:
In the field of cable modeling, many models have been proposed to describe the mechanical behavior of simple straight strands under axial loading, and the predictions of these models have been compared to experimental data when available. However, the validity domain of these models has not been evaluated yet because the experimental results reported in the literature are very limited. This problem is addressed here, the results from nine linear elastic models of a $6+1$ wire single layered strand (simple straight strand) subjected to static axial loads being compared with values from 3D finite element modeling. The analytical models are shown to give satisfactory estimations of the elastic stiffness constants for lay angles below $20^{\circ}$.
\end{abstract}

Keywords: Cable; Strand; Wire; Analytical model; Finite element 


\section{Nomenclature}

$R_{c}, R_{w}, R_{k}:$ core, wires and wires centerline radius

$k_{r}:$ ratio of wire radius to core radius

$\alpha$ : lay angle

$P$ : pitch length

$A$ : cross section area

$I$ : bending inertia modulus

$J$ : torsion inertia modulus

$u_{z}, \theta_{z}:$ overall axial displacement and rotation angle

$u_{z, z}, \theta_{z, z}$ : overall axial strain and twist angle per unit length

$u_{t, t}:$ wire axial strain

$\Delta k^{\prime}, \Delta \tau$ : changes in curvature and twist per unit length in the wire

$F_{z}, M_{z}:$ overall axial force and torque

$f_{z}, m_{\mathrm{z}}:$ non-dimensional axial force and torque

$F_{b}^{i}, F_{t}^{i}, M_{b}^{i}, M_{t}^{i}$ : shear force, traction force, bending moment and torque in the $\mathrm{i}^{\text {th }}$

wire

$k_{\varepsilon \varepsilon}, k_{\theta \theta}, k_{\varepsilon \theta}, k_{\theta \varepsilon}:$ axial stiffness coefficients of traction, torsion and couplings

$\bar{k}_{\varepsilon \varepsilon}, \bar{k}_{\theta \theta}, \bar{k}_{\varepsilon \theta}, \bar{k}_{\theta \varepsilon}:$ non-dimensional axial stiffness coefficients

$E, G$ : Young's and shear moduli

$v$. Poisson's ratio

$\zeta_{i}, \eta_{i}, \lambda_{i}, \mu_{i}:$ Knapp's parameters [12]

Subscripts $c$ and $w$ referring to core and wire characteristics, respectively 


\section{Introduction}

Helically wound fibers or wires constitute a large class of important engineering components (Cardou and Jolicoeur [1]). There are many kinds of such structure: one is the strand, defined as a structure made up of layers of helical wires wound around a central straight wire core. A wire rope is a structure made up of layers of strands wrapped helically around a central straight strand core. It is then possible to consider wire rope as a basic component to form a new wire rope with more complex cross section.

It is well known that a major advantage of such elements is their ability to support large axial loads with comparatively small bending or torsion stiffness. These structures play an essential role in various civil engineering applications, including the prestressing of concrete, stays for guyed masts, bridging applications such as hangers for suspension bridges as well as for mooring many offshore oil platforms.

Experimental work on large diameter cables requires specific, large and expensive testing devices. Design tools allowing rapid estimation of the overall axial elastic stiffness of stranded structures are therefore essential for designers. As will be detailed below, several analytical models based on different hypotheses (purely tension wires, curved beam theory, Poisson's ratio effects, friction effects and variations in core radius) have been developed and presented in the literature. However, comparisons between these models and corresponding discussion of their validity domain is not available in the literature. Nevertheless, it may be noted that the authors have usually compared their models with the experimental results reported in the earlier works. Jolicoeur and Cardou [2] compared the results obtained by several 
mathematical models available in the literature with the experimental $1+6$ cables results reported by Utting and Jones $[3,4]$, for six different lay angle $\left(9.2^{\circ}, 11^{\circ}, 12.2^{\circ}\right.$, $12.9^{\circ}, 14^{\circ}$ and $17^{\circ}$ ). Since the experimental results are very limited, obtaining a general conclusion is difficult.

The objective of the present study is to assess the validity domain of several analytical models for the elastic static axial (tension and torsion) behavior of a simple straight metallic strand (single-layered), consisting of six helical wires wrapped around a straight core. The influence of the assumptions of different analytical models will be discussed using comparisons with a complete three-dimensional formulation: a 3D finite element modelling has been used as a reference.

In section 2, a description of the geometry of the structures studied and the corresponding axial elastic overall behavior matrix form are given. Next, the existing mechanical models assumptions and corresponding stiffness coefficient expressions are given in section 3 .

In section 4, a three-dimensional finite element model is presented and FE results are compared with experimental data. In order to determine the validity domain, the stiffness matrix components are calculated using the selected analytical models. Then, the analytical results are compared with the FE model results, considered as a reference. 


\section{Strand overall behavior}

Let us consider a single $6+1$ straight strand cable made of six helical wires with a circular cross-section wrapped around a straight core as illustrated in Figure 1. The geometry is characterized by the core radius $R_{c}$, the wires radius $R_{w}$, and the lay angle $\alpha$ measured with respect to the cable z-axis. The wires centerline is then a helical curve of radius $R_{h}$ :

$$
R_{h}=R_{c}+R_{w}
$$

It can be noted that the wire cross-sections, due to contact forces with the core, are bean-shaped but can be approximated by ellipses in the plane perpendicular to the structure $\mathrm{z}$-axis (see figure 1). The pitch length denoted by $P$ can be calculated using the following expression:

$$
P=\frac{2 \pi R_{h}}{\tan \alpha}
$$

The axial behavior of such a structure exhibits coupling between tension and torsion due to the helical design of the wires. Thus, the elastic overall behavior can be expressed in the form:

$$
\left\{\begin{array}{c}
F_{z} \\
M_{z}
\end{array}\right\}=\left[\begin{array}{ll}
k_{\varepsilon \varepsilon} & k_{\varepsilon \theta} \\
k_{\theta \varepsilon} & k_{\theta \theta}
\end{array}\right]\left\{\begin{array}{c}
u_{z, z} \\
\theta_{z, z}
\end{array}\right\}
$$


where ${ }_{z, z}$ denotes the overall axial strain, $\theta_{z, z}$ the twist angle per unit length, $F_{z}$ the axial force and $M_{z}$ the torque. The four stiffness matrix components $k_{\varepsilon \varepsilon}, k_{\theta \theta}, k_{\theta \varepsilon}$ and $k_{\varepsilon \theta}$ are pure tensile, torsion and coupling terms respectively. Moreover, the stiffness matrix should be symmetric, as can be shown from Betti's reciprocal theorem, cf. [5].

\section{Analytical models}

\subsection{Overview}

As previously indicated, several analytical models are available to predict the mechanical behavior of isotropic cables subjected to axial loads, based on knowledge of the component material behavior and geometry of the structure. The first approaches only incorporate effects associated with tension, the bending and torsion stiffness of the wires being neglected. Such analyses have been performed by Hruska [6-8] and by Knapp [9] for a rigid core. McConnell and Zemek [10] modified this model, simply by considering the torsional stiffness of all the individual wires.

More recent and complex analytical models are based on beam theory assumptions: the wires are modelled using Love's curved beam equations [11]. Following this approach, Machida and Durelli [12] have studied the effects of the bending and torsion stiffness of individual wires on the cable stiffness matrix. Knapp [13] studied the effect of variations in core radius (due to the pressure from the layers). Costello and Philips [14] presented a general non-linear theory for a layer of 
helical wound wires without core, which included the effects of radius and lay angle variations (due to Poisson's ratio effect). This model was later extended by Philips and Costello [15] and Velinsky [16] to apply to wire rope with internal wire rope cores. Then, Costello [17] presented a linearized theory including the effects of curvature and twist variations. Kumar and Cochran [18] have developed a linearized form of this theory, leading to a closed-form expression for stiffness matrix components. Kumar and Botsis [19] have extended this model to obtain the analytical expression for the maximum contact stresses induced in the multilayered strands with metallic wire core. Huang [20] studied the contact mode conditions (radial or lateral) for $1+6$ cable. Local contact deformation is neglected whilst the Poisson's effect is included. It is found that radial contact seems to be the prevailing case, even when no initial gap exists between wires in the layers. Utting and Jones [3, 4] have extended the Costello's analysis to include wire flattening (contact deformation) and friction effects. The results show that these phenomena have very little effect on estimates of the global cable response.

Sathikh et al. [21] presented a closed form symmetric linear elastic model for a cable with a rigid core, using discrete thin rod theory. Labrosse [22] presented a new analytical approach to predict the overall behavior of $1+6$ cables subjected to bending, tension and torsion. In this model, Poisson's ratio effect is neglected while relative motions between core and wires are considered.

Elata et al. [23] presented a new model for simulating the mechanical behavior of a wire rope with an independent wire rope core under axial loads. In contrast with previous models that consider the effective response of wound strands, this model 
considers the complete double-helix configuration of individual wires within the wound strand and directly relates the wire level stress to the overall load applied at the rope level. Bending and torsion stiffness of the individual wires are neglected, but the wires are subjected to loads on their lateral surface, applied by adjacent wires. Therefore, the accuracy of this model increases when the number of wires in the wire rope increases. It should be noted that its major interest is to analyze the effect of a double helix configuration which is not the case here (in the 7 wire cable geometry). Moreover, this model does not lead to closed-form equations, and therefore will not be applied in the present paper.

Another approach for multi-layered cables consists of modeling each layer as an equivalent orthotropic sheet. This homogenization method was first applied to cable modelling by Hobbs and Raoof [24], and it has been described in detail by Raoof [25] and then extended by Raoof and his associates over two decades [24-29]. The same approach can also be used by replacing each layer with a cylinder of orthotropic, transversely isotropic material [30-34]. Such homogenization approaches can be applied when the number of wires in the layer is large, but this is not the case for $1+6$ structures.

In addition, several models are also available for the analysis of synthetic cables. Leech et al. [35], presented a quasi-static analysis of fiber ropes and included it in commercial software: Fiber Rope Modeller or FRM. Another model was developed by Rungamornrat et al. [36], and later extended by Beltran et al. [37] and Beltran and Williamson [38]. These models are very similar to that of Leech but they have concentrated on a damage model to take into account the degradation of rope 
properties as a function of loading history. These models are also implemented in a computer program. Very recently, Ghoreishi et al. [39, 40] have developed two closed-form analytical models which can be used in sequence to analyze the synthetic cables.

In this work, the case of a simple straight strand, with linear elastic behavior, isotropic material and axial loading, is considered.

\subsection{Descriptions of the analytical models}

As shown previously, there are several mathematical models that are based on different assumptions. In this section, nine analytical models have been selected and are described in more detail. These models are based on different assumptions, such as:

- Axial stiffness of wire is only considered,

- Bending and torsion stiffness of wire are included,

- Poisson's ratio effect is considered,

- Inter-wire contact (relative motion between core/wire) is considered.

The equations for each model are then briefly presented in a standardized form, using the same notations as those of Ghoreishi et al. [41].

\subsubsection{Hruska's model}


In the models based on pure tension wire, bending and torsion stiffness of the individual wires are neglected. Using purely geometrical relations, wire axial strain, $u_{t, t}$, can be expressed as follows:

$$
u_{t, t}=u_{z, z} \cos ^{2} \alpha+R_{h} \theta_{z, z} \sin \alpha \cos \alpha
$$

where $u_{z, z}$ and $\theta_{z, z}$ represent axial strain of cable and angle of twist per unit length, respectively. The stiffness matrix components are:

$$
\left\{\begin{array}{l}
k_{\varepsilon \varepsilon}=(A E)_{c}+6(A E)_{w} \cos ^{3} \alpha \\
k_{\varepsilon \theta}=k_{\theta \varepsilon}=6(A E)_{w} R_{h} \cos ^{2} \alpha \sin \alpha \\
k_{\theta \theta}=(G J)_{c}+6(A E)_{w} R_{h}^{2} \sin ^{2} \alpha \cos \alpha
\end{array}\right.
$$

where $(A E)$ and $(G J)$ represent axial and torsional stiffness respectively. The core and wires characteristics are denoted using subscripts $c$ and $w$ respectively.

This stiffness matrix has been obtained by Hruska [6-8] and re-derived by Knapp [9] for a rigid core.

\subsubsection{Model of McConnell and Zemek}

McConnell and Zemek [10] modified Hruska's model by adding the sum of the torsion stiffness of all the individual wires into Equation $(5)_{3}$. The equation of $k_{\theta \theta}$ then becomes: 


$$
k_{\theta \theta}=(G J)_{c}+6(G J)_{w}+6(A E)_{w} R_{h}^{2} \sin ^{2} \alpha \cos \alpha
$$

The relations for $k_{\varepsilon \varepsilon}, k_{\varepsilon \theta}$ and $k_{\theta \varepsilon}$ in Eqs. (5) remain identical.

\subsubsection{Model of Machida and Durelli}

Machida and Durelli [12] have studied the effects of the bending and torsion stiffness of individual wires on the cable stiffness matrix. They obtained the bending and twisting moments of each individual wire, then by projecting on the cable axis, and summing for all the wires, one obtains:

$$
\left\{\begin{array}{l}
k_{\theta \varepsilon}=6\left((A E)_{w} R_{h} \cos ^{2} \alpha \sin \alpha-2 \frac{(E I)_{w}}{R_{h}} \cos ^{2} \alpha \sin ^{3} \alpha+\frac{(G J)_{w}}{R_{h}} \cos ^{2} \alpha \sin \alpha\left(1-2 \cos ^{2} \alpha\right)\right) \\
k_{\theta \theta}=(G J)_{c}+6\left((A E)_{w} R_{h}^{2} \sin ^{2} \alpha \cos \alpha+2(E I)_{w} \cos ^{3} \alpha \sin ^{2} \alpha+(G J) \cos ^{3} \alpha\left(1-2 \sin ^{2} \alpha\right)\right)
\end{array}\right.
$$

where $(E I)$ is the bending stiffness of the wire. The relations for $k_{\varepsilon \varepsilon}$ and $k_{\varepsilon \theta}$ in Equation (5) remain identical. Thus stiffness matrix symmetry is lost.

\subsubsection{Knapp's model}

Knapp [13] presented a new stiffness matrix for straight cables subjected to tension and torsion. He studied the compressibility of the central core. The equilibrium equations first include geometric non-linearity and are then linearized to give a linear stiffness matrix. This approach was primarily aimed at soft core cables. 
However, thanks to a general derivation, Knapp's results can also be applied to the more rigid core cables considered in the present work.

In the present notations, stiffness matrix components can be written as:

$$
\left\{\begin{array}{l}
k_{\varepsilon \varepsilon}=(A E)_{c}+6(A E)_{w} \cos ^{3} \alpha \zeta \\
k_{\varepsilon \theta}=6(A E)_{w} R_{h} \sin \alpha \cos ^{2} \alpha \eta \\
k_{\theta \varepsilon}=6\left[(A E)_{w} R_{h} \sin \alpha \zeta-\frac{(E I)}{R_{h}}(\lambda+2 \zeta)\left(\sin ^{3} \alpha+\frac{(G J)}{R_{h}}(1-2 \zeta) \sin \alpha \cos ^{2} \alpha\right]\right. \\
k_{\theta \theta}=(G J)_{c}+6\left[\begin{array}{l}
\left.(A E)_{w} R_{h} \eta \sin \alpha-\frac{\left(E I_{w}\right)}{R_{h}}\left(\mu+2 \eta-\frac{2 R_{h}}{\tan \alpha}\right) \sin ^{3} \alpha\right] \\
+\frac{\left(G J_{w}\right)}{R_{h}}\left(\frac{R_{h}}{\tan \alpha}-2 \mu\right) \sin \alpha \cos ^{2} \alpha
\end{array}\right]
\end{array}\right.
$$

where $\zeta_{i}, \eta_{i}, \lambda_{i}$ and $\mu_{i}$ are parameters defined by Knapp in his paper, related to the geometric and elastic properties of the cables. In the present work, for steel core cable the compressibility of the central core is negligible, $\zeta_{i}$ and $\eta_{i}$ are very close to $\cos ^{2} \alpha$ and $R_{h} \sin \alpha \cos \alpha$, respectively, while $\lambda_{i}$ and $\mu_{i}$ are nearly equal to zero (see Ref. [13]). If these limiting values are substituted into equation (8), these reduce exactly to Machida and Durelli's results.

\subsubsection{Costello's model}

Costello's theory [17], based on Love's curved beam equations, takes into account the effects of radius and lay angle variations, as well as wire bending and torsion moments. The equilibrium is expressed using a set of non-linear equations which is also valid for large deflection. In the case of simple straight strands, it is 
assumed that change in lay angle is small. It follows that the cable axial strain $u_{z, z}$ and twist $\theta_{z, z}$, as well as changes in curvature and twist per unit length, $\Delta k^{\prime}$ and $\Delta \tau$, in each wire are linearized with respect to $\Delta \alpha$. Considering the development detailed in Ref. [17], the relationships for each wire may be written as:

$$
\left\{\begin{array}{l}
u_{z, z}=u_{t, t}+\Delta \alpha \tan \alpha \\
R_{h} \theta_{z, z}=u_{t, t} \tan \alpha-\Delta \alpha+v \tan \alpha \frac{\left(R_{c} u_{z, z}+R_{w} u_{t, t}\right)}{R_{h}} \\
R_{w} \Delta k^{\prime}=-\frac{2 \sin \alpha \cos \alpha}{R_{h} / R_{w}} \Delta \alpha+v \frac{R_{c} u_{z, z}+R_{w} u_{t, t}}{R_{h}} \frac{\sin ^{2} \alpha}{R_{h} / R_{w}} \\
R_{w} \Delta \tau=\frac{1-2 \cos ^{2} \alpha}{R_{h} / R_{w}} \Delta \alpha+v \frac{R_{c} u_{z, z}+R_{w} u_{t, t}}{R_{h}} \frac{\sin \alpha \cos \alpha}{R_{h} / R_{w}}
\end{array}\right.
$$

and the local mechanical behavior of each wire is given by:

$$
\left\{\begin{array}{l}
M_{t}^{i}=(G J)_{w} \Delta \tau \\
M_{b}^{i}=(E I)_{w} \Delta k^{\prime} \\
F_{t}^{i}=(E A)_{w} u_{t, t}^{w} \\
F_{b}^{i}=M_{t}^{i} \frac{\sin ^{2} \alpha}{R_{h}}-M_{b}^{i} \frac{\sin \alpha \cos \alpha}{R_{h}}
\end{array}\right.
$$

where $F_{b}^{i}, F_{t}^{i}, M_{b}^{i}$ and $M_{t}^{i}$ denote shear force, traction force, bending moment and torque in the $\mathrm{i}^{\text {th }}$ wire, respectively; moreover, $\Delta k^{\prime}$ and $\Delta \tau$ represent changes in curvature and twist per unit length, respectively and $u_{t, t}$ is the axial strain in an outer wire. Projecting on the cable axis and summing for all the wires, one gets: 


$$
\left\{\begin{array}{l}
F_{z}=(E A)_{c} u_{z, z}+6\left(F_{t}^{i} \cos \alpha+F_{b}^{i} \sin \alpha\right) \\
M_{z}=(G J)_{c} \theta_{z, z}+6\left(M_{t}^{i} \cos \alpha+M_{b}^{i} \sin \alpha+R_{h} F_{t}^{i} \sin \alpha+R_{h} F_{b}^{i} \cos \alpha\right)
\end{array}\right.
$$

To obtain the stiffness matrix components, the first two equations (9) $)_{1-2}$ allow the axial strain of the wire, $u_{t, t}$, and the variation of lay angle, $\Delta \alpha$, to be expressed as a function of global strain of the strand, $u_{z, z}$ and $\theta_{z, z}$. It follows that the changes in curvature and twist per unit length, $\Delta k^{\prime}$ and $\Delta \tau$, are also expressed as a function of these strains. Then, the local mechanical behavior of each wire can be expressed as a function of global strain of the strand, $u_{z, z}$ and $\theta_{z, z}$. Finally, by substituting equations (10) into equations (11), the global behavior of the strand can be obtained.

It should be noted that, recently, a closed-form expression of the cable stiffness matrix coefficients, has been given by Ghoreishi [42]. Moreover, in this model, the stiffness matrix symmetry is lost.

\subsubsection{Model of Kumar and Cochran}

Kumar and Cochran [18] have linearized the equations of Costello's model, and arrived at a closed-form expression for the stiffness matrix. In the present notation, the stiffness matrix components may be written as:

$$
\left\{\begin{array}{l}
k_{\varepsilon \varepsilon}=(A E)_{c}+6(A E)_{w} \cos \alpha\left(1-(1+v) p \sin ^{2} \alpha\right) \\
k_{s \theta}=6(A E)_{w} R_{h} p \cos ^{2} \alpha \sin \alpha \\
k_{\theta \varepsilon}=6\left((A E)_{w} R_{h} \sin \alpha-\frac{(E I)_{w}}{R_{h}} \sin \alpha\left(1-v_{f} \cos ^{4} \alpha+(1+v)\left(q-1+v_{f} \cos ^{4} \alpha\right)\right)\right. \\
k_{\theta \theta}=(G J)_{c}+6(E I)_{w} q \cos \alpha
\end{array}\right.
$$


where $p$ and $q$ are given by:

$$
\left\{\begin{array}{l}
p=\left(1-v_{1}\right)\left[1-(1 / 4)\left(\frac{R_{w}}{R_{h}}\right)^{2}\left(1+v_{f} \cos 2 \alpha\right) \sin ^{2} \alpha\right] \\
q=\left(1-v_{1}\right)\left[4\left(\frac{R_{h}}{R_{w}}\right)^{2} \sin ^{2} \alpha+1-\sin ^{4} \alpha-v_{f} \cos ^{4} \alpha \cos 2 \alpha\right]
\end{array}\right.
$$

in this relation $v_{1}$ and $v_{f}$ are obtained as follows:

$$
\left\{\begin{array}{l}
v_{1}=v\left(R_{w} / R_{h}\right) \sin ^{2} \alpha \\
v_{f}=v /(1+v)
\end{array}\right.
$$

The stiffness matrix symmetry is also lost.

\subsubsection{Ramsey's model}

Ramsey [43, 44] has proposed a mathematically rigorous approach based on differential geometry. Constitutive equations $(10)_{1-2}$, in which internal moments are linearly related to the curvature and twist variations $\Delta k^{\prime}$ and $\Delta \tau$, are replaced by:

$$
\left\{\begin{array}{l}
M_{t}^{i}=(G J)_{w}\left(\Delta \tau+\tau u_{t, t}\right) \\
M_{b}^{i}=(E I)_{w}\left(\Delta k^{\prime}+k^{\prime} u_{t, t}\right)
\end{array}\right.
$$


For axial loads, as indicated by Jolicoeur and Cardou [2], most equations reduce to Costello's model except for the foregoing differences. To evaluate their influence, equations ( 15$)_{1-2}$, have been used instead of equations $(10)_{1-2}$ in Costello's model.

\subsubsection{Sathikh's model}

Sathikh et al. [21] concentrated on the lack of symmetry in the earlier models. They developed a symmetric linear elastic model for simple straight strands, using Ramsey's theory and discrete thin rod theory. A simple straight strand with a rigid core and having only core to wire contact has been analyzed taking into account the wire tension, twist and bending together, for its response due to axisymmetric loads (traction-torsion). Following modification to the present notation, Sathikh's relations may be written as:

$$
\left\{\begin{array}{l}
k_{\varepsilon \varepsilon}=(A E)_{c}+6\left((A E)_{w} \cos ^{3} \alpha+\left[(G J)_{w} \sin ^{2} \alpha+(E I)_{w} \cos ^{2} \alpha\right] \frac{\sin ^{4} \alpha \cos \alpha}{R_{h}^{2}}\right) \\
k_{\varepsilon \theta}=k_{\theta \varepsilon}=6\left((A E)_{w} R_{h} \cos ^{2} \alpha \sin \alpha+\left[(G J)_{w} \cos ^{2} \alpha-(E I)_{w}\left(1+\cos ^{2} \alpha\right)\right] \frac{\sin ^{3} \alpha \cos ^{2} \alpha}{R_{h}}\right) \\
k_{\theta \theta}=(G J)_{c}+6\left[(A E)_{w} R_{h}^{2} \sin ^{2} \alpha \cos \alpha+(G J)_{w} \cos ^{7} \alpha+(E I)_{w} \sin ^{2} \alpha \cos \alpha\left(1+\cos ^{2} \alpha\right)^{2}\right]
\end{array}\right.
$$

\subsubsection{Labrosse's model}

Recently Labrosse [22] presented a new analytical approach to predict the global response of a cable subjected to bending, tension and torsion. In this theory the wires are considered as curved beams as presented by Love [11]. The integrated 
stresses over the cable cross section and the inter-wire efforts have been presented as a function of the generalized strains of the cable and derivation of the inter-wire slippage.

For the axial loads (tension and torsion), the stiffness matrix components become:

$$
\left\{\begin{array}{l}
k_{\varepsilon \varepsilon}=(A E)_{c}+6(A E)_{w} \cos ^{3} \alpha \\
k_{\varepsilon \theta}=k_{\theta \varepsilon}=6(E A)_{w} R_{h} \sin \alpha \cos ^{2} \alpha \\
k_{\theta \theta}=(G J)_{c}+6\left((E A)_{w} R_{h}^{2} \sin ^{2} \alpha \cos \alpha+(G J)_{w} \cos ^{5} \alpha+(E I)_{w} \sin ^{2} \alpha \cos \alpha\left(1+\cos ^{2} \alpha\right)\right)
\end{array}\right.
$$

The selected analytical models with their principal features (i.e., behavior of wire, change in geometry due to Poisson's effect, symmetric matrix and closed form solution), are summarized in table 1.

\section{Numerical study}

Emphasis is placed on the linear elastic global behavior of a simple isotropic straight steel strand under small strain. To evaluate their validity domains, the matrix stiffness coefficients obtained from the analytical models presented in the previous section are compared with those calculated from a complete 3D formulation: the overall behavior of the strand has also been calculated using a 3D FE model detailed hereafter. The results are expressed in a general non-dimensionalized form and for strand lay angle $\alpha$ varying between 2.5 and $35^{\circ}$, which cover the usual practical values. The investigation of local effects (i.e. stress distribution in the cross section, contact deformation, local plastic yielding) is not included in this paper. 


\subsection{FE approach}

\subsubsection{Background}

With the development of finite element methods during the last decades, together with the development of computer capacity, certain authors have used the finite element approach to analyze the mechanical behavior of cables. Carlson [45], modeled the wires by bar elements as well as the connections between the wires. Cutchins [46], used solid elements (6 node) to model the wires, their connections were simulated with springs. Nawrocki [47] presented a one dimensional curved beam element for analyzing the simple straight strand $(1+6)$ and later Nawrocki and Labrosse [48] studied the relative motions between core and the wires, using this element. They have shown that the inter-wire pivoting and the inter-wire sliding govern the cable global response, for axial and bending loads, respectively. It should also be underlined that some FE studies have focussed on local phenomena: Jiang et al. $[49,50]$ investigated the stress distribution within the wires, in a simple straight strand as well as in a three layered straight strand, using a concise 3D finite element model with prescribed displacement field. One can mention also the work of Wehking and Ziegler [51] devoted to the detailed computation of rope stresses. In the same way, Messager and Cartraud [52] have developed an homogenization procedure: applying the rigorous asymptotic development theory, a slice of a strand can be studied using a 3D FE model free of any displacement assumption. In the present paper, a complete 3D FE model is presented as a reference to determine the validity domain of existing analytical models. 


\subsubsection{Description of the model}

The simple straight strand cable structure has been computed using the COSMOS FE code, Version 2.0. The geometry of the core has been obtained by a linear $z$-axis extrusion. Each wire has been generated by the extrusion of a circular surface along an helical curve corresponding to the centroidal line of the wire. As shown in figure 2 , each wire section consists of twelve finite elements (six 15-node and six 20-node solid elements). It should be noted that the number of elements along the strand z-axis varies with lay angle because of the pitch length variations in this range of lay angle, for example, pitch length of $769.4 \mathrm{~mm}$ and $41.9 \mathrm{~mm}$ for lay angle of $2.5^{\circ}$ and $35^{\circ}$ respectively.

The boundary conditions are defined as follows:

- One end-section of the cable is fully clamped.

- At the other end-section, the wires and the core nodes are linked using rigid body elements connected to a master node located at the cross-section center.

- On this master node, the transverse loads and bending moments are prescribed to be zero.

The " $6+1$ " cable structure considered is illustrated in figure 2 . It is assumed that the wires do not touch each other (no wire/wire contact) in the undeformed state so contact is only present radially (core/wire contact). Moreover, Huang [20] has shown that even if the wires are in radial contact in the undeformed state, they tend to separate while loading. 
In addition, in a preliminary study, the influence of contact conditions between the wires and the core (wire/core contact) has been examined for two limit cases: sliding without friction and merging. These contact conditions have been applied for nodes situated on the helical lines of contact between core and wires. The results obtained show that the static overall behavior is not sensitive to these modeling hypotheses. Indeed, the relative difference between these limit cases, for stiffness matrix components, is less than $1.5 \%$ (for lay angle varying between 2.5 and 35 ). Therefore, for the results detailed thereafter in section 4.2 , the contact nodes have been merged. However, it should be mentioned that while the friction effect plays a small role in global stiffness behavior of such structures, the effect of friction on the long-term performance and durability of a structure under cyclic loading can be significant.

The stiffness coefficients are computed in four successive steps corresponding to different loading conditions in tension and torsion on the master node:

$k_{\varepsilon \varepsilon}:$ an axial load $F_{z}$ is applied while the rotation angle $\theta_{z}$ is prescribed to zero.

$k_{\theta \theta}:$ a torque $M_{z}$ is applied whereas the axial displacement $u_{z}$ is locked

$k_{\varepsilon \theta}:$ axial load $F_{z}$ with a free rotation angle $\theta_{z}$.

$k_{\theta \varepsilon}$ : torque $M_{z}$ with a free axial displacement $u_{z}$.

The cable strains are calculated from the master node axial displacement and rotation. Preliminary tests, performed for models of lengths between two and ten pitches, have demonstrated that the overall axial response is not influenced by end 
effects. The results detailed in next paragraphs have been obtained for an FE model consisting (for each value of the lay angle $\alpha$ ) of only two pitch lengths. It should be underlined that the discrepancies observed on the coupling terms $k_{\varepsilon \theta}$ and $k_{\theta \varepsilon}$ have been found to be negligible for all FE analyses performed, the differences were always less than $0.4 \%$.

It should be mentioned that, the numerical convergence has been verified with respect to:

- Number of elements per pitch

- Axial length of the model (number of pitch in the model)

\subsubsection{Comparisons with experiments}

To demonstrate the accuracy of FEM results, the results of the 3D FE model are compared with the experimental data, reported by Utting and Jones [3, 4]. In the experimental study material modulus determined from tests on wires and core has been measured to be $197.9 \mathrm{GPa}$, cf. [3]. In the FEM model isotropic material is considered, the Young modulus $E$ and the Poisson's ratio have been set to $197.9 \mathrm{GPa}$ and 0.3 , respectively.

First, the stiffness matrix components are computed using a 3D FE model for three strands which were studied by Utting and Jones in Refs. [3, 4]. Then, numerical results are compared with the experimental data. It should be noted that the experimental results do not allow a comparison of the stiffness matrix components directly, so different parameters will be compared for different tests as will be explained below. 
Utting and Jones [4] have performed an experimental study on simple straight steel strands with six different lay angles (for all of them: $R_{c}=1.97$ and $R_{w}=1.865 \mathrm{~mm}$ ). Nominally fixed-end tests, as well as the tests with free and partially restrained ends were carried out. The rotations were measured during a load range of $40 \mathrm{kN}$ for free end tests. This rotation can also be calculated by the following expression:

$$
\theta_{z, z}=\frac{F_{z}}{k_{\varepsilon \theta}-\frac{k_{\varepsilon \varepsilon} k_{\theta \theta}}{k_{\theta \varepsilon}}} \text {, for free end condition. }
$$

For nominally fixed-end tests, the torque generated was recorded. Table 2 compares measured values with FE results for nominally fixed end and free end conditions.

It should be noted that, for nominally fixed end tests in which the rotation, theoretically, should be zero, but during the tests, some small rotations, ${ }_{z, z}$, were reported and attributed by the authors to resin deformation at the end fittings of the cables, namely, $0.064,0$ and $0.058 \mathrm{rad} / \mathrm{m}$ for specimen number 1,4 and 6 , respectively, see Utting and Jones [3, 4]. Thus, numerical values (in table 2) have been obtained by solving equation (3) for $M_{z}$, with the given values of $F_{z}$ and $\theta_{z, z}$, using the stiffness matrix components which were obtained from the 3D FE model. For the fixed end condition, the twisting moment, $M_{z}$, can be expressed as follows:

$$
M_{z}=\frac{k_{\theta \varepsilon}}{k_{\varepsilon \varepsilon}}\left(F_{z}-k_{\varepsilon \theta} \theta_{z, z}\right)+k_{\theta \theta} \theta_{z, z}, \text { for fixed end condition. }
$$


The intermediate case where both an axial load and twisting moment are imposed was also considered. Axial strain, $u_{z, z}$, and twist per unit length, $\theta_{z, z}$, of the strand are then measured. If the axial load is fixed, say $40 \mathrm{kN}$, and the torque is given two values $M_{z}^{1}$ and $M_{z}^{2}$, one gets two sets of results $\left(u_{z, z}^{1}, \theta_{z, z}^{1}\right)$ and $\left(u_{z, z}^{2}, \theta_{z, z}^{2}\right)$. Defining $\Delta M_{z}=M_{z}^{2}-M_{z}^{1}, \Delta u_{z, z}=u_{z, z}^{2}-u_{z, z}^{1}, \Delta \theta_{z, z}=\theta_{z, z}^{2}-\theta_{z, z}^{1}$, one can calculate slopes $\Delta M_{z} / \Delta u_{z, z}$ and $\Delta M_{z} / \Delta \theta_{z, z}$. These slopes can also be given by the following expressions:

$$
\left\{\begin{array}{l}
\frac{\Delta M_{z}}{\Delta u_{z, z}}=k_{\theta \varepsilon}-\frac{k_{\varepsilon \varepsilon} k_{\theta \theta}}{k_{\varepsilon \theta}} \\
\frac{\Delta M_{z}}{\Delta \theta_{z, z}}=k_{\theta \theta}-\frac{k_{\theta \varepsilon} k_{\varepsilon \theta}}{k_{\varepsilon \varepsilon}}
\end{array}\right.
$$

Table 3 presents such slopes measured by tests and prediction by the FE model.

In general, tables 2 and 3, indicate a good correlation between the FE model and experiment, at least for the range of lay angles considered here.

So, once the numerical reliability of the FEM model was checked convergence has been reached on the cable behavior - the modeling assumptions elliptical shape approximation for the wire cross-section, sticking contact between the wires and the core - have been validated through the comparison with experimental results. Experimental results are available only for lay angle values of 9.2, 12.2 and $17^{\circ}$, but the FEM model is not restricted to those lay angles. Due to the lack of published experimental data (particularly for larger lay angles), hereafter the 3D FE results will be considered as a reference solution.

\subsection{Results and discussion}


In order to perform general comparisons for lay angle varying between 2.5 and $35^{\circ}$, the stiffness matrix component values obtained both using the analytical formulations and the 3D FE model have been expressed using a non-dimensional form. Considering Eq. (3), this may be written as:

$$
\left\{\begin{array}{l}
f_{z} \\
m_{z}
\end{array}\right\}=\left[\begin{array}{cc}
\bar{k}_{\varepsilon \varepsilon} & \bar{k}_{\varepsilon \theta} \\
\bar{k}_{\theta \varepsilon} & \bar{k}_{\theta \theta}
\end{array}\right]\left\{\begin{array}{c}
u_{z, z} \\
\theta_{z, z} \cdot R_{h}
\end{array}\right\}
$$

where the reduced loading components are defined by:

$$
\left\{\begin{array}{l}
f_{z}=\frac{F_{z}}{E \cdot \pi \cdot R_{h}^{2}} \\
m_{z}=\frac{M_{z}}{E \cdot \pi \cdot R_{h}^{3}}
\end{array}\right.
$$

The non-dimensional components of the stiffness matrix are then expressed as follows:

$$
\left\{\begin{array}{l}
\bar{k}_{\varepsilon \varepsilon}=\frac{k_{\varepsilon \varepsilon}}{E \cdot \pi \cdot R_{h}^{2}} \\
\bar{k}_{\theta \theta}=\frac{k_{\theta \theta}}{E \cdot \pi \cdot R_{h}^{4}} \\
\bar{k}_{\varepsilon \theta}=\frac{k_{\varepsilon \theta}}{E \cdot \pi \cdot R_{h}^{3}} \\
\bar{k}_{\theta \varepsilon}=\frac{k_{\theta \varepsilon}}{E \cdot \pi \cdot R_{h}^{3}}
\end{array}\right.
$$


As can be shown from any analytical model, the post-processed $\bar{k}_{i j}$ axial stiffness coefficients turn out to be dependent on only two geometrical characteristic values: lay angle $\alpha$ and ratio of wire radius to core radius $k_{r}=R_{w} / R_{c}$. Moreover, these dimensionless coefficients $\bar{k}_{i j}$, are independent of the elasticity modulus $E$ of the constitutive material; the only material term characterizing the isotropic material behavior is the Poisson's ratio value. For the present numerical preliminary study, this coefficient has been taken to be 0.3 . Ghoreishi [42] performed a sensitivity study for these geometrical characteristics ( $\alpha$ and $k_{r}$ ), which demonstrates that the accuracy of the models is not sensitive to $k_{r}$ for the usual practical values. Therefore, the results obtained using the different models are compared only for lay angle variation.

Figure 3 details the evolutions of the non-dimensional axial stiffness, $\bar{k}_{\varepsilon \varepsilon}$, obtained by different analytical models as well as 3D finite element model, versus lay angle.

These curves show that all the analytical models studied here produce only two distinct series of results: there is a coincidence of the results for the models of Hruska [8], Machida and Durelli [12], McConnell and Zemek [10], Sathikh et al. [21] and Labrosse [22] (the differences are negligible and only one curve has been plotted for these 5 models), and another series of results for Kumar and Cochran [18], Ramsey [44] and Costello [17]. It may be noted that for the second group of models, the change of geometry due to the Poisson's effect is taken into account. However, the non-dimensional axial stiffness remains a little higher than those of FE model. In addition, for the small lay angles $\left(\alpha \leq 15^{\circ}\right)$, the results of all the models are very close (within $1.7 \%$ of each other), and a good agreement is obtained with the FE model 
(always less than $5 \%$ difference). The difference between these groups of models increases slightly with increasing lay angle. Moreover, the models which take into account the change of geometry due to the Poisson's effect, give the results closest to FE model values, see figures 3,4 and 5 .

Figure 4 shows the non-dimensional torsion term versus lay angle. These results were obtained by selected analytical models and the 3D finite element model. As shown in figure 4, the model of Hruska [8] gives results appreciably lower than the others, because the torsional stiffness of the wires is neglected. This effect is more important when the lay angle is small. This can be easily explained by the fact that an increase in lay angle also increases considerably the torsional stiffness, while having little or no effect on the $(G J)_{w}$ or $(E I)_{w}$ terms. This effect is especially noticeable for a single layered strand because in a multi-layered strand, the torsional stiffness of the wire is negligible when compared to the term contributed from axial load.

All the other analytical models provide very similar results, the difference increasing slightly with increasing lay angle. In addition, for $\alpha \leq 20^{\circ}$, the agreement between the analytical models (except Hruska's model) and FE model are encouraging. Beyond this value, a significant difference appears.

Let us note finally that the simple modification to the model of Hruska made by McConnell and Zemek [10], gives results which are quite comparable to those of much more complex models, as has already been noted by Jolicoeur and Cardou [2]. 
The evaluation of the non-dimensional coupling terms $\bar{k}_{\varepsilon \theta}$ and $\bar{k}_{\theta \varepsilon}$, versus lay angle, are illustrated in figures 5 a) and b) respectively. As underlined previously, only the models of Hruska, Sathikh and Labrosse lead to symmetrical matrix terms $\left(\bar{k}_{\varepsilon \theta}=\bar{k}_{\theta \varepsilon}\right)$.

For $\bar{k}_{\varepsilon \theta}$, we can make the same qualitative analysis as in the case of the axial stiffness. The results of the analytical models are grouped in two series, whose difference increases slightly with the lay angle. For a small angle $\left(\alpha \leq 15^{\circ}\right)$, the agreement with the FE model is very good. Beyond this value, a significant difference appears (up to $45 \%$ ). With regard to $\bar{k}_{\theta \varepsilon}$, (see figure 5 b), the differences between the results of the analytical models are more significant. In addition, when the lay angle increases, it appears that the models which take into account the change of geometry due to the Poisson's effect, also give the results closest to those of the FE model.

\section{Concluding remarks}

The objective of this paper is to determine the validity domain of analytical models of steel strands. The elastic behavior of a simple $6+1$ geometry having lay angles up to $35^{\circ}$ and subjected to axial static load has been studied. First, the equations of nine selected models have been rewritten with the same notation, and their principal assumptions have been briefly presented. It was shown that the $3 \mathrm{D} F E$ model can be used as a reference for the cable behavior since its results are very close to existing experimental data. 
Then, the results of selected models are compared with those of 3D FE model calculations, using general dimensionless stiffness coefficients.

Considering these results, the $\bar{k}_{i j}$ values are in good agreement, (except for the model of Hruska which clearly underestimates the torsional stiffness), for lay angle values below $20^{\circ}$. The relative differences between analytical and FEM results are then always less than $10 \%$. Nevertheless, the discrepancies grow rapidly and significantly, except in the case of the axial stiffness, for $\alpha$ values beyond $20^{\circ}$. These differences then become significant (up to $45 \%$ ) especially for the coupling terms $\bar{k}_{\varepsilon \theta}$ and $\bar{k}_{\theta \varepsilon}$. It is possible that in this range of lay angle curved beam theory is too approximate for the helical wire analysis. From the point of view of accuracy, it appears that for lay angles below $15^{\circ}$, there is a negligible difference between analytical models. For lay angles beyond $15^{\circ}$, the analytical models which take into account the change of geometry due to the Poisson's effect, Kumar and Cochran [18], Ramsey [44] and Costello [17], provide the results closest to those of 3D FE model. However, these models present the disadvantage of having a nonsymmetrical stiffness matrix.

In conclusion, the analytical models presented here appear quite satisfactory for the estimation of the elastic stiffness coefficients of $6+1$ metallic strand structures with lay angles less than $20^{\circ}$. This is an important conclusion for designers and has allowed the domain of validity of models for these structures to be quantified in terms of finite element results, instead of relying on experimental data. For larger lay angles the use of 3D FE modeling would be recommended. 


\section{References}

[1] Cardou A, Jolicoeur C. Mechanical models of helical strands. Appl. Mech. Rev. 1997; $50(1): 1-14$.

[2] Jolicoeur C, Cardou A. A numerical comparison of current mathematical models of twisted wire cables under axisymmetric loads. Journal of Energy Resources Technology 1991; 113 (1): 241-249.

[3] Utting WS, Jones N. The Response of Wire Rope Strands To Axial Tensile LoadsPart I. Experimental Results and Theoretical Predictions. International Journal of Mechanical Sciences 1987; 29 (9): 605-619.

[4] Utting WS, Jones N. The Response of Wire Rope Strands To Axial Tensile LoadsPart II. Comparison of Experimental Results and Theoretical Predictions. International Journal of Mechanical Sciences 1987; 29 (9): 621-636.

[5] Samras RK, Shop RA, Milburn DA. An analysis of coupled extensional-torsional oscillations in wire ropes. Journal of Engineering for Industry 1974; 74: 1130-1135.

[6] Hruska FH. Calculation of stresses in wire ropes. Wire and wire products 1951;26 (9): 766-767.

[7] Hruska FH. Radial forces in wire ropes. Wire and wire products 1952; 27 (5): 459463.

[8] Hruska FH. Tangential forces in wire ropes. Wire and wire products 1953; 28 (5): $455-460$.

[9] Knapp RH. Nonlinear Analysis of a Helically Armored Cable With Nonuniform Mechanical Properties in Tension and Torsion. In: proceeding of IEEE/MTS conference of Engineering in the ocean Environment, San Diego, 1975. p. 55-164. 
[10] McConnell KG, Zemeke WP. A Model to Predict the Coupled Axial Torsion Properties of ACSR Electrical Conductors. Journal of Experimental Mechanics 1982; 22: $237-244$.

[11] Love AEH. A treatise on the mathematical theory of elasticity. New York, Dover Publications, 1944.

[12] Machida S, Durelli AJ. Response of a Strand to Axial and Torsional Displacements. Journal of Mechanical Engineering science 1973; 15: 241-251.

[13] Knapp RH. Derivation of a new stiffness matrix for helically armoured cables considering tension and torsion. International Journal for Numerical Methods in Engineering 1979; 14: 515-520.

[14] Costello GA, Philips JW. Effective Modulus of twisted wire cables. ASCE, Journal of the Engineering Mechanics Division 1976; 102: 171-181.

[15] Philips JW, Costello GA. Analysis of Wire Rope With Internal-Wire-Rope Cores. ASME Journal of Applied Mechanics 1985; 52: 510-516.

[16] Velinsky SA. General Nonlinear Theory for Complex Wire rope. International Journal of Mechanical Sciences 1985; 27: 497-507.

[17] Costello GA. Theory of wire rope, 2nd edition, Springer: New York, N.Y, 1997.

[18] Kumar K, Cochran Jr JE. Closed-Form Analysis for Elastic Deformations of Multilayered Strand. ASME J. Applied Mechanics 1987; 54: 898-903.

[19] Kumar K, Botsis J. Contact Stresses in Multilayered Strands Under Tension and Torsion. Journal of applied Mechanics 2001; 68: 432-440.

[20] Huang NC. Finite extension of an elastic strand with a core. Journal of Applied Mechanics 1978; 45: 852-858. 
[21] Sathikh S, Moorthy MBK, Krishnan M. A symmetric Linear Elastic Model for Helical Wire Strands under Axisymmetric Loads. Journal of Strain Analysis 1996; 31 (5): 389-399.

[22] Labrosse M. Contribution à l'étude du rôle du frottement sur le comportement et la durée de vie des câbles monocouches. PhD thesis, Ecole Centrale de Nantes, France, 1998.

[23] Elata D, Eshkenazy R, Weiss MP. The mechanical behavior of a wire rope with an independent wire rope core. International Journal of Solids and Structures 2004; $41(5): 1157-1172$.

[24] Hobbs RE, Raoof M.. Interwire slippage and fatigue prediction in stranded cables for TLP tethers. Behaviour of Offshore Structures, Hemisphere publishing/McGrawHill, New York, 1982; 2: 77-99.

[25] Raoof M. Interwire contact forces and the static, hysteretic and fatigue properties of multi-layer structural strands. PhD thesis, Imperial Collage of Science and Technology, London, UK, 1983.

[26] Raoof M, Hobbs RE. Analysis of Multilayered Structural Strands. Journal of engineering Mechanics 1988; 114 (7): 1166-1182.

[27] Raoof M. Method for analysing large spiral strands. Journal of Strain Analysis $1991 ; 26(3): 165-174$.

[28] Raoof M, Kraincanic I. Simple Derivation of the Stiffness Matrix for Axial/Torsional Coupling of Spiral Strands. Computers and Structures 1995; 55 (4): $589-600$.

[29] Raoof M, Kraincanic I. Analysis of Large Diameter Steel Ropes. Journal of Engineering Mechanics 1995; 121 (6): 667-675. 
[30] Blouin, F, Cardou, A. A study of helically reinforced cylinders under axially symmetric loads mathematical modelling. International Journal of Solids and Structures 1989; 25 (2): 189-200.

[31] Jolicoeur C, Cardou A. An analytical solution for bending of coaxial orthotropic cylinders. Journal of Engineering Mechanics 1994; 120 (12): 2556-2574.

[32] Jolicoeur C, Cardou A. Semicontinuous Mathematical Model For Bending of Multylayered Wire Strands. Journal of engineering Mechanics 1996; 122 (7): 643650.

[33] Crossley JA, Spencer AJM, England AH. Analytical solutions for bending and flexure of helically reinforced cylinders. International Journal of Solids and Structures 2003; 40 (4): 777-806.

[34] Crossley JA, England AH, Spencer AJM. Bending and flexure of cylindrically monoclinic elastic cylinders. International Journal of Solids and Structures 2003; 40 (25): 6999-7013.

[35] Leech CM, Hearle JWS, Overington MS, Banfield SJ. Modelling Tension and torque Properties of Fibre Ropes and Splices. In: Proceeding of the Third International Offshore and Polar Engineering Conference Singapore, 1993.

[36] Rungamornrat J, Beltran JF, Williamson EB. Computational Model for Synthetic-Fiber Rope Response. In: Proceeding of fifteenth Engineering Mechanics Conference, ASCE, New York, 2002.

[37] Beltran JF, Rungamornrat J, Williamson EB. Computational model for the analysis of damage ropes. In: Proceedings of The thirteenth International Offshore and Polar Engineering Conference, Honolulu, Hawai, US A, 2003. 
[38] Beltran JF, Williamson EB. Investigation of the Damage-Dependent Response of Mooring Ropes. In: Proceedings of The Fourteenth International Offshore and Polar Engineering Conference Toulon, France, 2004.

[39] Ghoreishi SR, Cartraud P, Davies P, Messager T. Analytical modeling of synthetic fiber ropes subjected to axial loads. Part I : A new continuum model for multilayered fibrous structures. Accepted in: International Journal of Solids and Structures 2006.

[40] Ghoreishi SR, Davies P, Cartraud P, Messager T. Analytical modeling of synthetic fiber ropes, part II: A linear elastic model for $1+6$ fibrous structures. Accepted in: International Journal of Solids and Structures 2006.

[41] Ghoreishi SR, Messager T, Cartraud P, Davies P. Assessment of Cable Models for Synthetic Mooring Lines. In: Proceedings of The Fourteenth International Offshore and Polar Engineering Conference Toulon, France, 2004. p. 184-190.

[42] Ghoreishi SR. Modélisation analytique et caractérisation expérimentale du comportement de câbles synthétiques. Ph.D. thesis, Ecole Centrale de Nantes, France, 2005.

[43] Ramsey H. A theory of thin rods with application to helical constituent wires in cables. International Journal of Mechanical Sciences 1988; 30 (8): 559-570.

[44] Ramsey H. Analysis of interwire friction in multilayered cables under uniform extension and twisting. International Journal of Mechanical Sciences 1990; 32 (8): 709-716.

[45] Carlson $\mathrm{AD}$, Kasper RG. A structural analysis of a multiconductor cable. technical report $\mathrm{AD}-767$ 963, Naval underwater system center, New London Laboratory, 1973. 
[46] Cutchins MA, Cochran JE, Guest S, Fitz-Coy NG, Tinker ML. An investigation of the damping phenomena in wire rope isolator. In: The Role of Damping in Vibration and Noise Control 1987; 5 (Boston, Massachusettes): 197-204, Proceedings of the 1987 ASME Design Technology Conference, 1987.

[47] Nawrocki A. Contribution à la modélisation des câbles monotorons par éléments finis. PhD thesis, Ecole Centrale de Nantes, France, 1997.

[48] Nawrocki A, Labrosse M. A finite element model for simple straight wire rope strands. Computers and Structures 2000; 77: 345-359.

[49] Jiang WG, Yao MS, Walton JM. A concise finite element model for simple straight wire rope strand. Int. J. of Mechanical Sciences 1999; 41 (2): 143-161.

[50] Jiang WG, Henshall JL, Walton JM. A concise finite element model for threelayered straight wire rope strand. Int. J. of Mechanical Sciences 2000; 42(1): 63-89.

[51] Wehking, K-H, Zieglen, S. Calculation of a standard rope with FEM. Wire 2004; 54 (2): 96-100.

[52] Messager T, Cartraud P., Homogenization of helical beam-like structuresApplication to single-walled carbon nanotubes submitted to Computational Mechanics, 2007. 


\section{Figures}

Figure 1: Geometry of a simple straight strand or $1+6$ structure.

Figure 2: Mesh examples.

Figure 3: axial stiffness, $\bar{k}_{\varepsilon \varepsilon}$, versus lay angle $\alpha$.

Figure 4: non-dimensional torsion term, $\bar{k}_{\theta \theta}$, versus lay angle $\alpha$.

Figure 5: dimensionless coupling terms versus $\alpha$, a) $\bar{k}_{\varepsilon \theta}$ and b) $\bar{k}_{\theta \varepsilon}$ 


\section{Tables}

Table 1: selected analytical models with their principal features.

\begin{tabular}{|c|c|c|c|c|c|c|}
\hline \multirow{2}{*}{ Models } & \multicolumn{3}{|c|}{ Behavior of wires } & \multirow{2}{*}{$\begin{array}{c}\text { Poisson's } \\
\text { effect }\end{array}$} & \multirow{2}{*}{$\begin{array}{c}\text { Symmetric } \\
\text { matrix }\end{array}$} & \multirow{2}{*}{$\begin{array}{l}\text { Closed-form } \\
\text { solution }\end{array}$} \\
\hline & Te. & To. & $\mathrm{Be}$. & & & \\
\hline HRU & $\mathrm{X}$ & --- & --- & --- & $\mathrm{X}$ & $\mathrm{X}$ \\
\hline MAC & $\mathrm{X}$ & $\mathrm{X}$ & $\mathrm{X}$ & --- & --- & $\mathrm{X}$ \\
\hline $\mathrm{McC}$ & $\mathrm{X}$ & $\mathrm{X}$ & --- & --- & --- & $\mathrm{X}$ \\
\hline KNA & $\mathrm{X}$ & $\mathrm{X}$ & $\mathrm{X}$ & --- & --- & $\mathrm{X}$ \\
\hline KUM & $\mathrm{X}$ & $\mathrm{X}$ & $\mathrm{X}$ & $\mathrm{X}$ & --- & $\mathrm{X}$ \\
\hline RAM & $\mathrm{X}$ & $\mathrm{X}$ & $\mathrm{X}$ & $\mathrm{X}$ & --- & --- \\
\hline SAT & $\mathrm{X}$ & $\mathrm{X}$ & $\mathrm{X}$ & -- & $\mathrm{X}$ & $\mathrm{X}$ \\
\hline $\operatorname{COS}$ & $\mathrm{X}$ & $\mathrm{X}$ & $\mathrm{X}$ & $\mathrm{X}$ & --- & $\mathrm{X}$ \\
\hline LAB & $\mathrm{X}$ & $\mathrm{X}$ & $\mathrm{X}$ & --- & $\mathrm{X}$ & $\mathrm{X}$ \\
\hline \multicolumn{4}{|c|}{ HRU: Hruska [7] } & \multicolumn{2}{|c|}{ RAM: Ramsey [43 } & \\
\hline \multicolumn{4}{|c|}{ MAC: Machida and Durelli [11] } & \multicolumn{3}{|c|}{ SAT: Sathikh [20] } \\
\hline \multicolumn{4}{|c|}{ McC: McConnell and Zemek [9] } & \multicolumn{3}{|c|}{ COS: Costello [16] } \\
\hline \multicolumn{4}{|c|}{ KNA: Knapp [12] } & \multicolumn{3}{|c|}{ LAB: Labrosse [21] } \\
\hline \multicolumn{4}{|c|}{ KUM: Kumar and Cochran [17] } & & & \\
\hline
\end{tabular}


Table 2: comparison between 3D FE model and experimental data (reported in Refs. [3, 4]), for nominally fixed and completely free end conditions.

\begin{tabular}{|l|c|c|c|c|c|c|c|}
\hline Specimen & \multicolumn{3}{|l|}{ Stiffness matrix components } & \multicolumn{2}{l|}{$M_{z}$ (N.m) } & \multicolumn{2}{l|}{$\theta_{z, z}(\mathrm{rad} / \mathrm{m})$} \\
& \multicolumn{2}{|l|}{ obtained by 3D FE model } & \multicolumn{2}{l|}{ (fixed end) } & \multicolumn{2}{l|}{ (free end) } \\
\cline { 2 - 9 } & $k_{\varepsilon \varepsilon}$ & $k_{\varepsilon \vartheta}=k_{\Im \varepsilon}$ & $k_{\theta \theta}$ & Test & FEM & Test & FEM \\
& $(\mathrm{kN})$ & N.m) & $\left(\mathrm{N} . \mathrm{m}^{2}\right)$ & & & & \\
\hline $1\left(\alpha=17^{\circ}\right)$ & $1.32 \mathrm{e} 3$ & $12.4 \mathrm{e} 3$ & 26.74 & 34.4 & 36.7 & 2.4929 & 2.50889 \\
\hline $4\left(\alpha=12.2^{\circ}\right)$ & $1.43 \mathrm{e} 3$ & $9.72 \mathrm{e} 3$ & 19.46 & 26 & 27.2 & 2.2049 & 2.12266 \\
\hline $6\left(\alpha=9.2^{\circ}\right)$ & $1.48 \mathrm{e} 3$ & $7.64 \mathrm{e} 3$ & 15.86 & 18.8 & 19.9 & 1.62025 & 1.73139 \\
\hline
\end{tabular}

Table 3: comparison between 3D FE model and experimental data reported in Refs. [3, 4] for partially restrained ends.

\begin{tabular}{|c|c|c|c|c|c|c|c|}
\hline \multirow[t]{2}{*}{ Specimen } & \multicolumn{3}{|c|}{$\begin{array}{l}\text { Stiffness matrix components } \\
\text { obtained by 3D FE model }\end{array}$} & \multicolumn{2}{|c|}{$\begin{array}{l}\Delta M_{z} / \Delta u_{z, z} \\
\left(10^{3} \text { N.m }\right)\end{array}$} & \multicolumn{2}{|c|}{$\begin{array}{l}\Delta M_{z} / \Delta \theta_{z, z} \\
\left(\mathrm{~N} \cdot \mathrm{m}^{2}\right)\end{array}$} \\
\hline & $\begin{array}{l}k_{\varepsilon \varepsilon} \\
(\mathrm{kN})\end{array}$ & $\begin{array}{l}k_{\varepsilon Q}=k_{Q \varepsilon} \\
\text { (N.m) }\end{array}$ & $\begin{array}{l}k_{\theta \theta} \\
\left(\mathrm{N} \cdot \mathrm{m}^{2}\right)\end{array}$ & Test* & FEM & Test* & FEM \\
\hline $1\left(\alpha=17^{\circ}\right)$ & $1.32 \mathrm{e} 3$ & $12.4 \mathrm{e} 3$ & 26.74 & 16.2 & 15.94 & 13.7 & 15.03 \\
\hline $4\left(\alpha=12.2^{\circ}\right)$ & $1.43 \mathrm{e} 3$ & $9.72 \mathrm{e} 3$ & 19.46 & 20.1 & 18.84 & 12.8 & 12.84 \\
\hline $6\left(\alpha=9.2^{\circ}\right)$ & $1.48 \mathrm{e} 3$ & $7.64 \mathrm{e} 3$ & 15.86 & 22.9 & 23.10 & 11.6 & 11.92 \\
\hline
\end{tabular}

* these results were given by Utting and Jones [3, 4], in graphical form. 


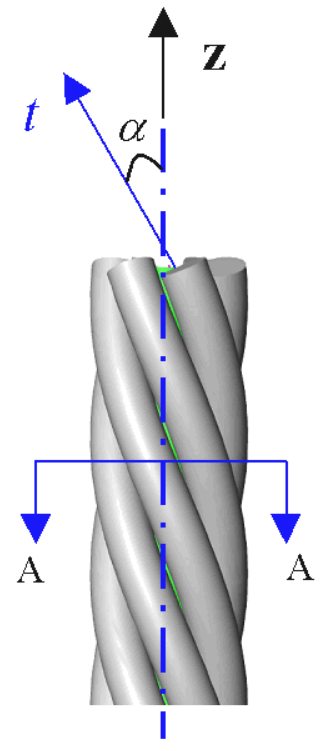

$1+6$ Structure

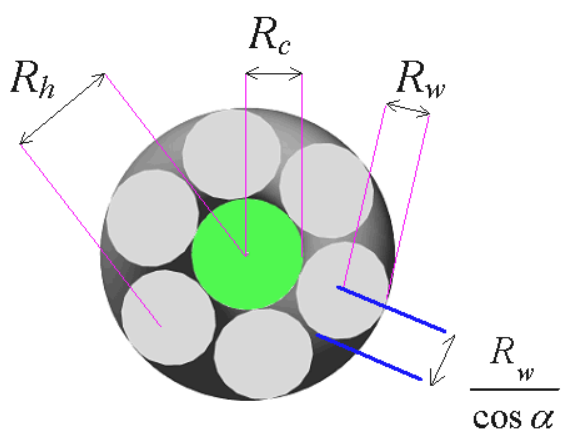

Structure cross section A-A

Figure 1: Geometry of a simple straight strand or $1+6$ structure. 


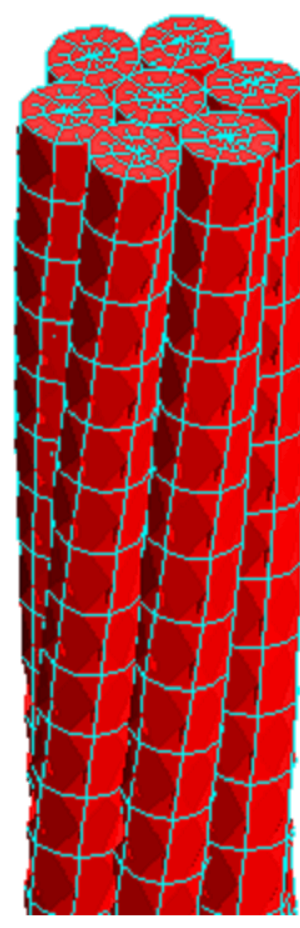

$\alpha=5^{\circ}$

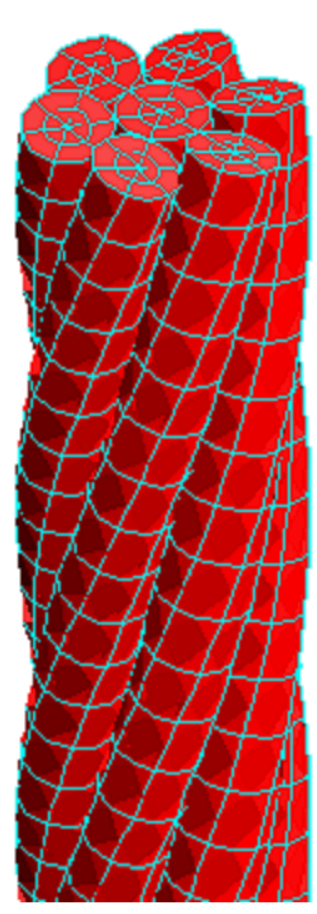

$\alpha=15^{\circ}$

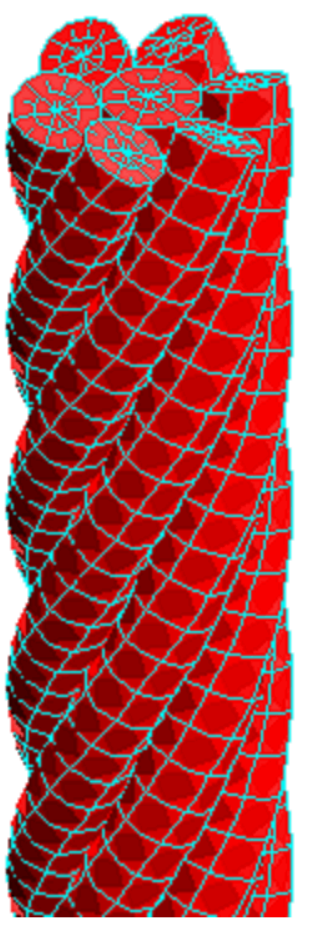

$\alpha=25^{\circ}$

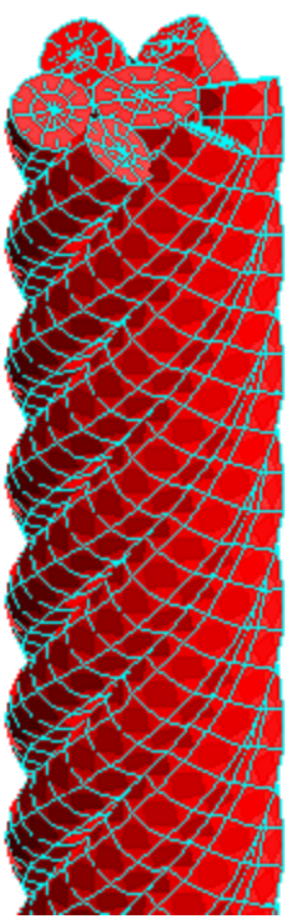

$\alpha=35^{\circ}$

Figure 2: Mesh examples. 


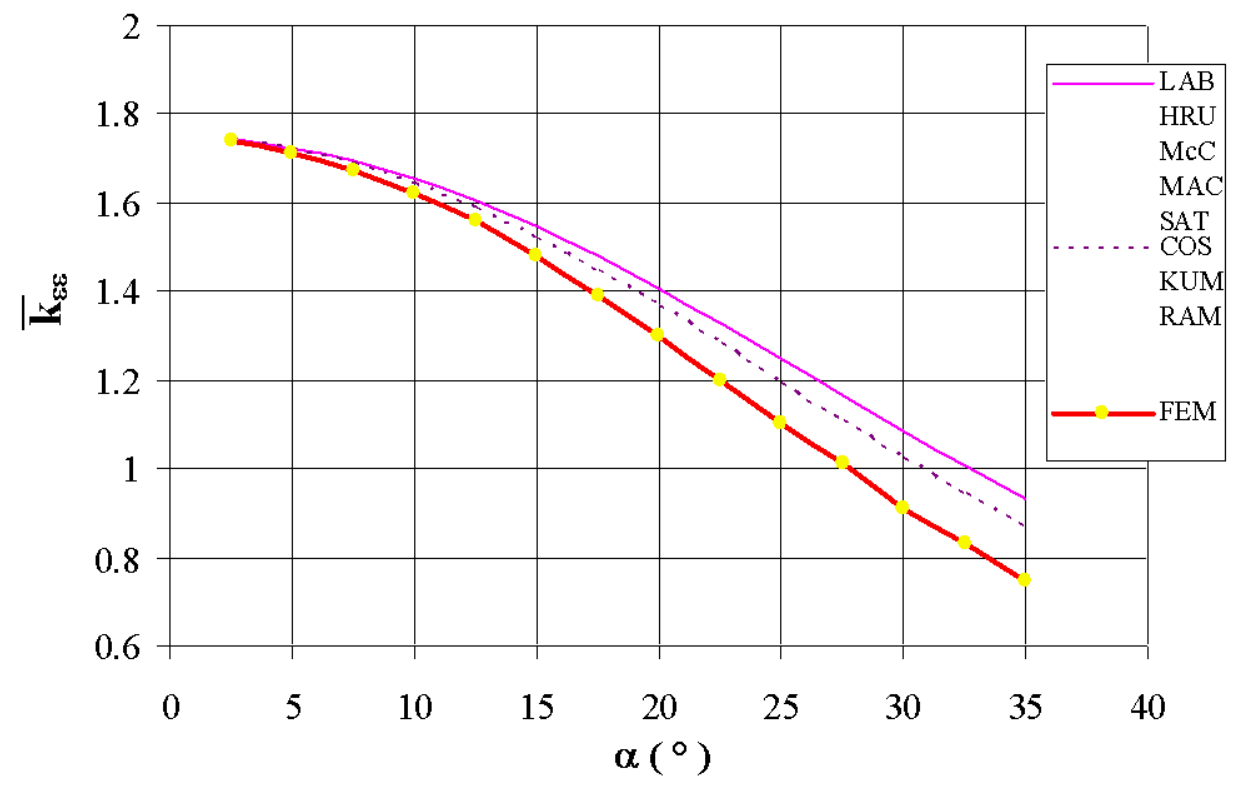

Figure 3: axial stiffness, $\bar{k}_{\varepsilon \varepsilon}$, versus lay angle $\alpha$. 


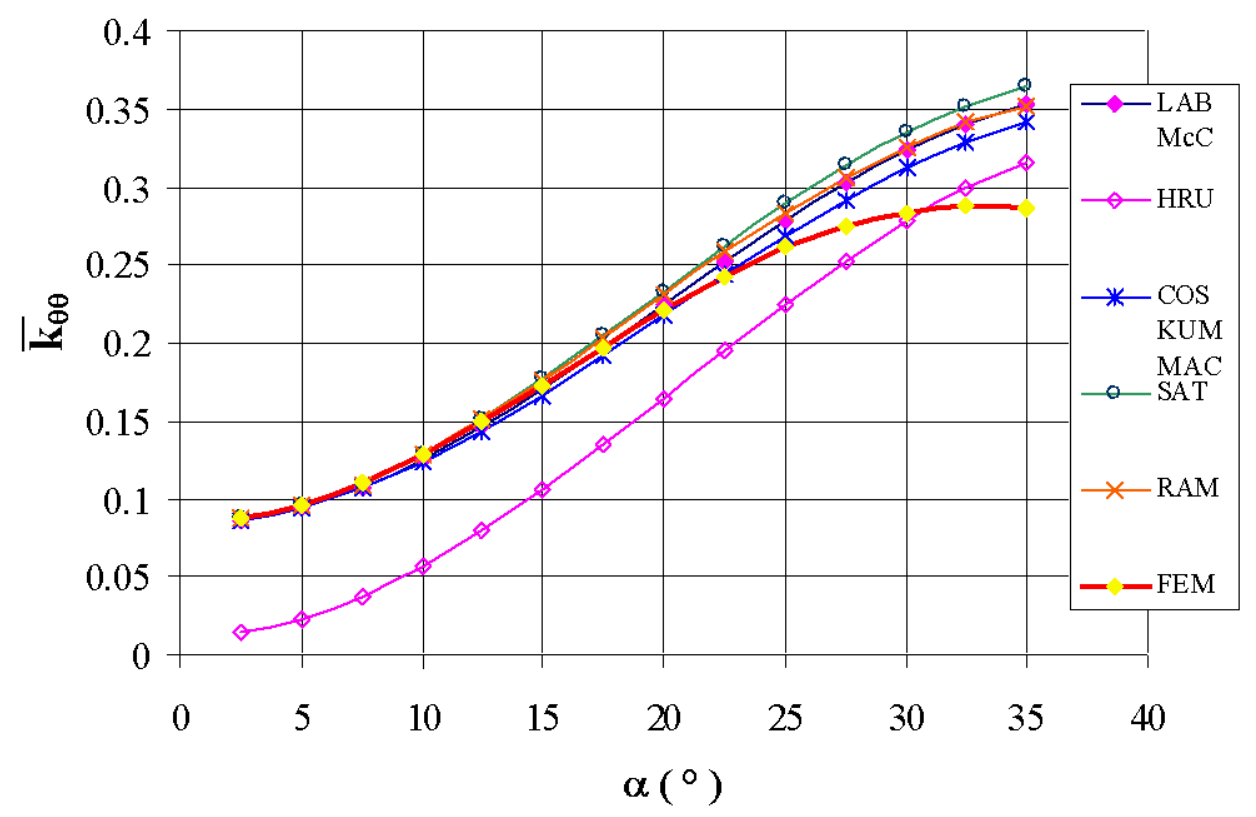

Figure 4: non-dimensional torsion term, $\bar{k}_{\theta \theta}$, versus lay angle $\alpha$. 


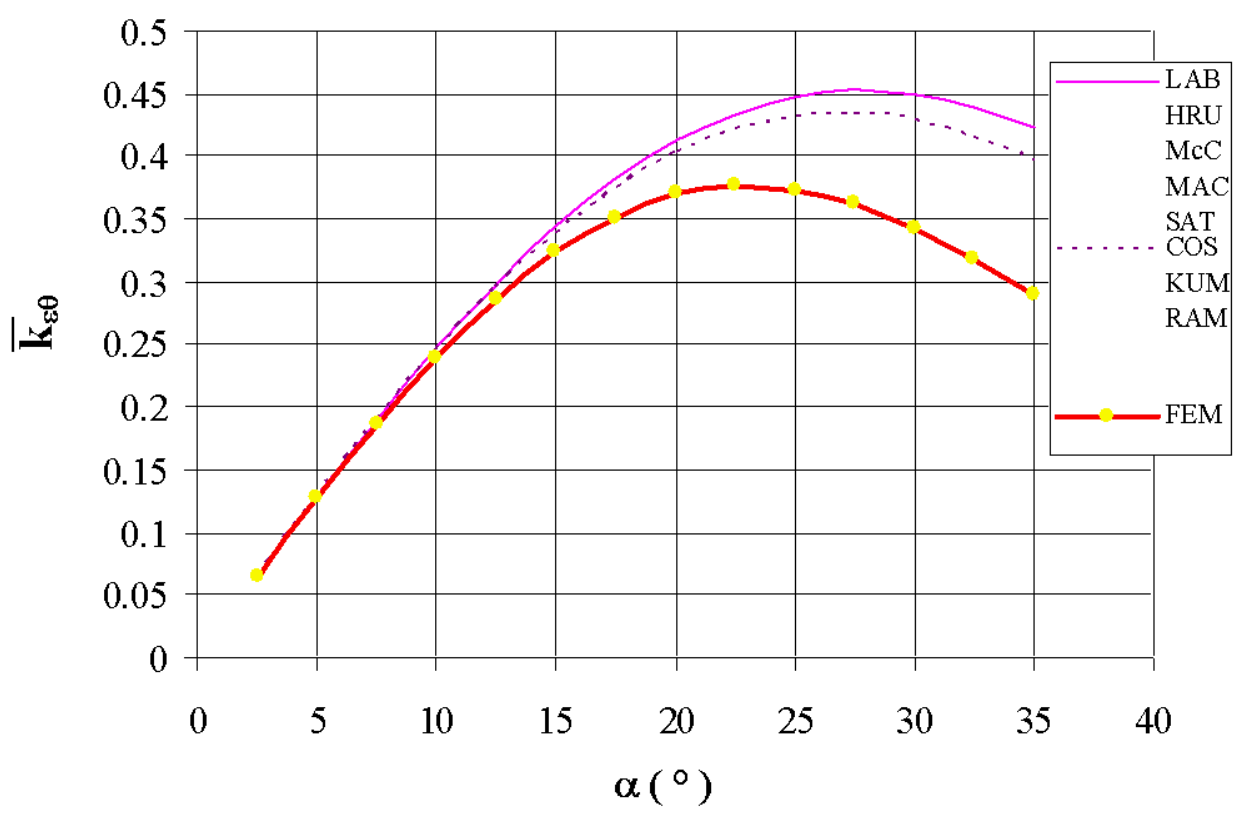

a)

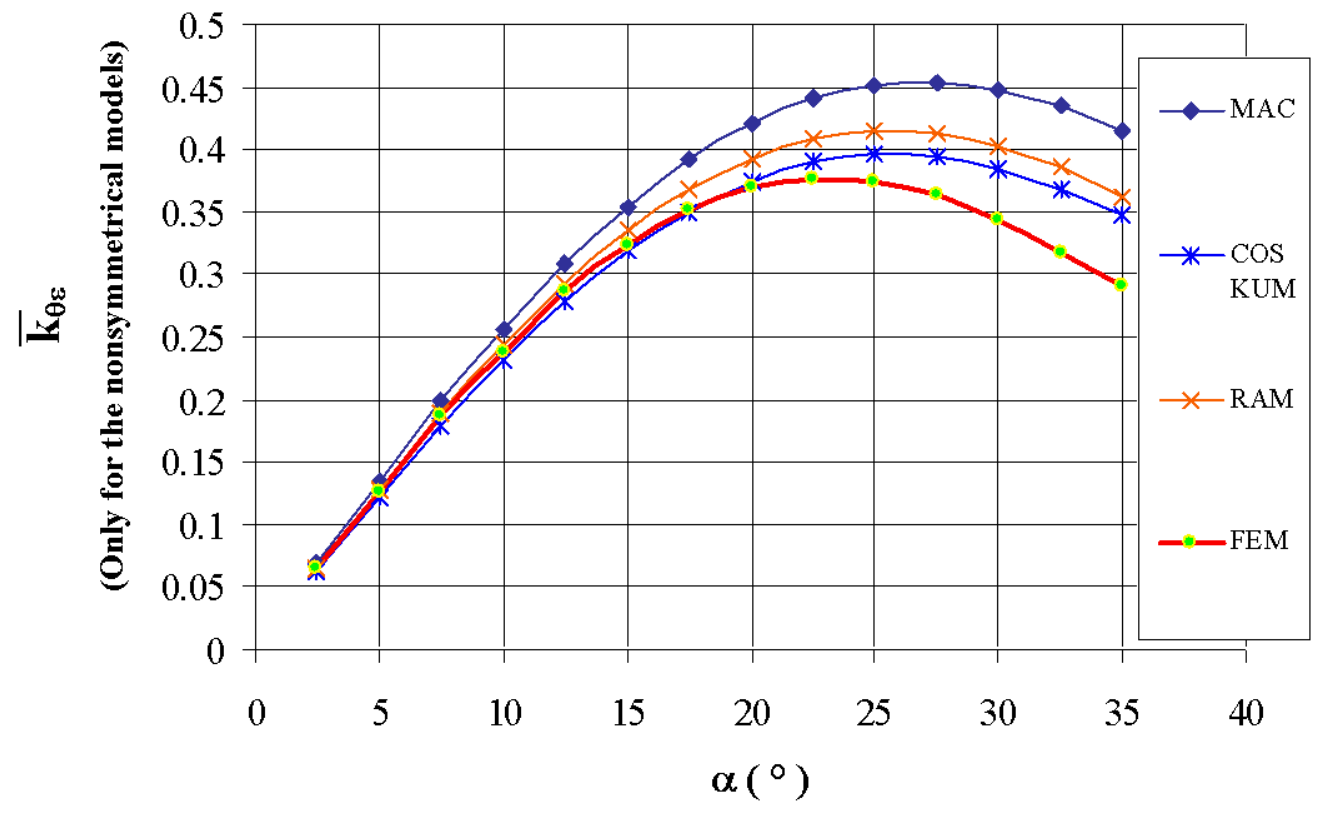

b )

Figure 5: dimensionless coupling terms versus $\alpha$, a) $\bar{k}_{\varepsilon \theta}$ and b) $\bar{k}_{\theta \varepsilon}$ 


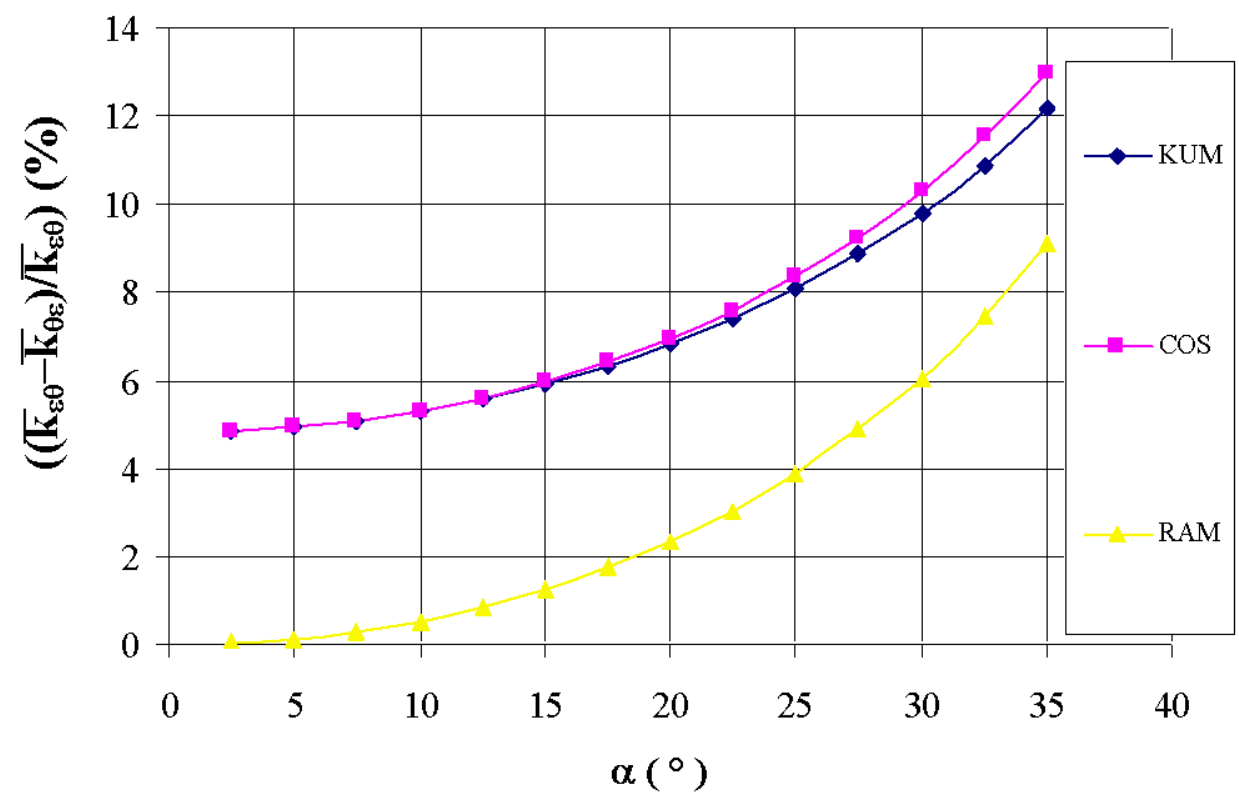

